\title{
Entrevista com Amelinha Teles: o nosso projeto é pela vida, Heleieth Saffioti na luta feminista
}

\author{
Raquel Oliveira Lindôso ${ }^{1}$ \\ https://orcid.org/0000-0002-8657-3955
}

\author{
Daniele Cordeiro Motta ${ }^{2}$ \\ https://orcid.org/0000-0002-7296-3688
}

${ }^{1}$ Universidade Estadual de Campinas, Programa de Pós-Graduação em Ciências Sociais, Campinas, SP, Brasil

${ }^{2}$ Instituto Federal de Educação, Ciência e Tecnologia de São Paulo, Capivari, SP, Brasil

Entrevista com Amelinha Teles: o nosso projeto é pela vida, Heleieth Saffioti na luta feminista. Resumo: Nesta entrevista, Amelinha Teles discorre sobre sua trajetória intelectual e militante iniciada durante a ditadura civil e militar no Brasil e a recepção do livro de Heleieth Saffioti (2013 [1969]), A mulher na sociedade de classes: mito e realidade, considerado por Amelinha como o primeiro livro feminista sobre mulheres escrito no Brasil. Ressalta-se a contemporaneidade do legado de Saffioti por meio das teorias do Nó das relações sociais de classe, gênero e raça/etnia e atualidade do Patriarcado. Discute-se, também, o diálogo íntimo entre Heleieth Saffioti e a luta feminista no Brasil, especialmente a atuação de Heleieth Saffioti junto às Promotoras Legais Populares (PLPs).

Palavras-chave: Luta feminista. Nó-relações sociais de classe, gênero e raça/etnia. Patriarcado. Promotoras Legais Populares (PLPs).

Interview with Amelinha Teles: our project is for life, Heleieth Saffioti in the feminist struggle Abstract: In this interview, Amelinha Teles discusses her intellectual and militant trajectory initiated during the civil and military dictatorship in Brazil and the reception of the book by Heleieth Saffioti (2013), The women in class society: myth and reality, considered by Amelinha as the first feminist book about women written in Brazil. The contemporaneity of Saffioti's legacy is emphasized through the theories of the Node of social relations of class, gender and race/ethnicity and the current status of the Patriarchate. It also discusses the intimate dialogue between Heleieth Saffioti and the feminist struggle in Brazil, especially the role of Heleieth Saffioti with the Popular Legal Promoters (PLPs).

Keywords: Feminist struggle. Node- social relations of class, gender and race/ethnicity. Patriarchate. Popular Legal Promoters (PLPs).

Este é um artigo publicado em acesso aberto (Open Access) sob a licença Creative Commons Attribution NonCommercial, que permite uso, distribuição e reprodução em qualquer meio, sem restrições desde que sem fins comerciais e que o trabalho original seja corretamente citado. 
Recebido em 28.04.2020. Aprovado em 13.07.2020. Revisado em 27.10.2020.

Maria Amélia de Almeida Teles é militante e intelectual feminista que publicou livros com foco nas temáticas da violência contra as mulheres, direitos humanos e direitos das mulheres, história do feminismo brasileiro e a política de creche. Amelinha atua na União de Mulheres de São Paulo e no projeto Promotoras Legais Populares (PLPs). A intelectual feminista atuou, também, na Comissão de Familiares de Mortos e Desaparecidos Políticos e na Comissão Nacional da Verdade (CNV) do Estado de São Paulo Rubens Paiva ${ }^{1}$.

Quando nós decidimos recuperar o legado intelectual e político de Heleieth Saffioti, sabíamos que o diálogo com a intelectual e militante feminista Amelinha Teles seria imprescindível para a compreensão desse legado, visto que Amelinha e Saffioti pertencem à geração que pensou a luta feminista no contexto histórico da ditadura civil e militar. Não por acaso escolhemos como caminho metodológico visitar a trajetória pessoalpolítica de Amelinha, objetivando conhecer, entre outras coisas, a repercussão da obra pioneira de Saffioti (2013[1969]), A Mulher na Sociedade de Classes: mito e realidade, no movimento de mulheres da época, especialmente no estado de São Paulo.

O diálogo com Amelinha Teles buscou, também, compreender a contribuição atual do pensamento de Heleieth Saffioti. E, nesse sentido, a teoria do Nó, que trata da imbricação das relações sociais de gênero, raça/ etnia e classe social, apresenta-se como questão central. Outra reflexão importante diz respeito à relevância atual do patriarcado no âmbito dos estudos de gênero e da práxis feminista.

Nesta entrevista, decidimos respeitar a linguagem de Amelinha Teles, já que o modo de construção da narrativa se desenvolve através da revisita à memória em conexão com fatos e reflexões situadas no tempo presente. Esse respeito tem a ver, também, com às relações de amizade, companheirismo e afetos, expressos em diversas momentos da entrevista, como por exemplo, nas repetidas vezes em que Amelinha chama Saffioti pelo seu primeiro nome, Heleieth.

Raquel Oliveira Lindôso: Para iniciarmos, gostaríamos que você falasse como foi o seu encontro com o feminismo e com o movimento social.

Amelinha Teles: O feminismo aparece para mim no ano de 1965, mas eu estava na clandestinidade. Eu vou me tornar uma feminista pública quando se proclama o ano de 1975, o Ano Internacional da Mulher, quando algumas brasileiras, em plena ditadura militar, aproveitam a chamada da Nações Unidas para falar em feminismo. Eu vou tomar conhecimento da palavra feminismo na clandestinidade. Porque eu vou ser uma militante contra a ditadura militar. Eu vou viver clandestina, vou ser presa e ter toda minha família presa. A minha geração marcou a vinda da Betty Fridman ${ }^{2}$ ao Brasil. [Betty] Foi no Pasquim ${ }^{3}$ e foi muito ridicularizada. Ela trouxe uma questão política extremamente instigante, porque as mulheres que ficavam sozinhas em casa, administrando ou realizando o trabalho doméstico, tinham um sentimento de vazio, de não fazer nada, sentimento de não participar da sociedade. As mulheres estavam bem à margem, e ela [Betty] falava das mulheres da classe média, mulheres brancas dos Estados Unidos. E isso incomoda, a gente vai começando a pensar. Eu sou muito leitora do Pasquim porque eu sou leitora de tudo quanto é jornal. Eu trabalho na imprensa clandestina e, então, todo o jornal eu tenho que ler, tenho que saber e tal. E o Pasquim era um jornal interessante.

Eu sou uma mulher que vem da classe trabalhadora e sempre trabalhei e sempre vivi do meu parco salário. Nós somos uma geração que, consciente ou não, a gente rompeu com os estereótipos. Sou uma mulher da época que a pílula foi descoberta, em 1960, e começa a ser usada. Eu sou da época que ser virgem, manterse virgem, quero dizer, fazer sexo só com aquela pessoa que tem certeza de que vai ser seu companheiro. A questão da lesbianidade era [considerada] uma doença. Enfim, eu participo de uma geração que mudou e rompeu com estereótipos muito rapidamente.

Daniele Cordeiro Motta: Nos anos 70 havia uma desconfiança com o feminismo. Heleieth Saffioti, na obra A mulher na sociedade de classes: mito e realidade, publicada em 1969, afirmou que não se tratava de uma obra feminista. De que maneira você analisa a relação dessa geração com o feminismo?

Amelinha Teles: Afirmar-se feminista é uma pressão muito grande, ainda mais na academia. Saffioti nega no Brasil Mulher ${ }^{4}$, porque naquela época éramos todas mal vistas. Na periferia, na academia, nos sindicatos e no movimento estudantil. Na época a gente compreendia que ser feminista pegava mal, já que era considerado pejorativo. Nós éramos discriminadas e isoladas. Nós falávamos em feminismo numa época em que era mais ou menos assim: ou você era sapatão - uma coisa era você ser lésbica, até era chique, mas sapatão [...] -, 
ou você era uma mulher perturbada, tresloucada, uma mulher meio terrorista, meio estranha. Eu lembro que um dia eu estava conversando com um cara, isso uns trinta e tantos anos atrás, eu falei que eu era feminista e ele: "Nossa! A senhora é feminista? Não parece. Como assim? Você parece uma pessoa tão sensata". Isso era muito comum, eu estou lembrando esse por acaso, mas houve muitas situações iguais a essa. Eu entendo perfeitamente a negação da Heleieth.

Raquel Oliveira Lindôso: E como você conheceu a Heleieth Saffioti?

Amelinha Teles: Em 1975 nos reunimos para fazer o jornal e discutir o feminismo. A gente era de uma ignorância terrível porque não tinha nada para ler. Eu lembro que um dia a gente recebeu um livro da Isabel Larguia ${ }^{5}$, que falava do trabalho invisível das mulheres e do trabalho doméstico. Todo mundo ficou apaixonado por esse livro. Não era livro e, sim, uma xerox. Na ditadura não havia livros de linha marxista. Os livros marxistas que vinham para o Brasil eram escritos em espanhol e editados em espanhol. Não havia livros em português, e [tínhamos] algumas xerox em inglês que faltavam letras. As [feministas] que estavam no exílio criticavam muito a gente, porque a gente era do feminismo muito atrasado. Então, "como a gente vai avançar nesse feminismo?" Os companheiros, os homens, criticavam demais e a gente tinha que buscar momentos para convencer os homens. Na mesma época, chegou a Juliet Mitchell ${ }^{6}$ e Shulamith Firestone ${ }^{7}$. Ambos em inglês. Nós líamos uns pedaços e contávamos umas para as outras. E aí, alguém falou que tinha uma mulher muito boa que tinha escrito um livro e que era do feminismo marxista ${ }^{8}$ E foi aí quando nos conhecemos. Os estudantes da USP ficaram sabendo que tinha esse livro da Heleieth Saffioti e trouxeram para nós no Brasil Mulher. E aí ficamos com a maior dificuldade para ler. [O livro] Era ruim demais para ler. Então decidimos fazer a leitura coletivamente. Fizemos uma coisa muito bonita estudando a obra de Heleieth. Nós fizemos uma roda, umas 30 mulheres, aí cada uma tirava um pedacinho, retornava para casa e estudava. Havia uma psiquiatra que aprendeu a fazer psicodrama. Cada pedaço transformava-se em um psicodrama. Era um negócio bonito e ajudou muito a gente a entender o livro. O melhorzinho foi a segunda parte ${ }^{9}$ que tratava das condições das mulheres e temas históricos, foi o que aproveitamos mais. E era contra o capitalismo, e nós já éramos mesmo contra o capitalismo.

[A mulher na sociedade de classes: mito e realidade é] o primeiro livro feminista sobre mulheres, depois que eu entendia que era feminista, que nos ajudou a argumentar com os machistas. As feministas da minha geração não eram da academia, mas queríamos ser intelectuais feministas, como é o meu caso. Não sei se chegamos a ser, mas queríamos. Esse livro foi básico para nós. Jamais posso falar que me tornei feminista ignorando a Heleieth. Sou eternamente grata a ela.

Logo em seguida, quando as mulheres estavam disputando espaços públicos eu conheci Heleieth Saffioti. A Heleieth Saffioti, presencialmente, era muito mais feminista do que nesse livro. Conheci Heleieth nos anos 80 e vou ser amiga da Heleieth até ela morrer, em 2010. Porque a Heleieth começa a vir para o movimento em 80, antes ela vai na Sociedade Brasileira do Progresso da Ciência, o SBPC, que ali tem muitas intelectuais feministas.

Heleieth é uma companheira! De 1990 até 2010 Heleieth Saffioti foi professora das Promotoras Legais Populares (PLPs). Heleieth ministrava aula sobre gênero, ou melhor, gênero sob a ordem patriarcal. Falava também sobre violência e teoria do Nó. Era muito interessante a aula.

Daniele Cordeiro Motta: Amelinha, você estava falando da clandestinidade e da relação com os homens do partido, podemos conversar mais sobre como essas disputas estavam colocadas no cotidiano da política?

Amelinha Teles: A discussão dentro do partido (refere-se ao PCdoB) era muito rasa, muito difícil, muito doutrinada. Eu até hoje vejo feministas de partido e penso "como elas aguentam ser feministas e ficar no partido?", porque a discussão é muito limitada. E comigo não era diferente, quando eu colocava a discussão feminista dentro do partido, o partido rejeitava o feminismo e me mandava ler o Lênin, Clara Zetkin, Inês Armand, Alexandra Kollontai... Eu tentava escrever algum artigo sobre as mulheres no jornal e era sempre barrado, com a justificativa de que não havia espaço para publicação, porque existiam matérias prioritárias. Então havia uma tendência a não publicar matérias sobre as mulheres, estou falando dos anos 70. O que nos ajudou a convencer e argumentar com os machistas de que o feminismo era necessário, foi esse livro [refere-se à obra $A$ mulher na sociedade de classes: mito e realidade]. 
Por exemplo, esse negócio de assédio no trem e ônibus, era o nosso cotidiano. Muitas vezes levávamos uma toalha, um pano, porque eles [os homens] esporravam nas nossas pernas. Eu viajei muito no trem da Central do Brasil, então você era esporrada e você tinha que limpar seu corpo naquele lugar sujo, para tentar ir trabalhar e fazer suas coisas. Isso fazia parte do nosso cotidiano. Porque isso tudo era naturalizado. Ninguém denunciava. Não denunciava porque você era mal vista. Então nossa terapia era totalmente solitária, porque você não ia ficar conversando sobre isso, ou então, às vezes, conversávamos com uma colega: "Sabe o que aconteceu comigo ontem?" Então a violência contra as mulheres acontecia naquela época e não podíamos falar dessa questão porque era [considerada] perda de tempo. "Vamos centrar no campesinato e proletariado... Mulheres?" Isso é coisa para superestrutura. Aí os homens aprenderam a exercer a prática patriarcal com a maior tranquilidade.

Raquel Oliveira Lindôso: Entrando um pouco nas categorias utilizadas por Heleieth Saffioti, o patriarcado é peça-chave para explicar a desigualdade entre homens e mulheres. Com a disseminação do conceito de gênero, a categoria patriarcado perdeu espaço. Você acha que o patriarcado ainda é importante para o movimento feminista?

Amelinha Teles: Eu também sou igual a ela [Saffioti], não sou teórica, mas concordo com Saffioti sobre as "relações de gêneros na ordem patriarcal". Porque gênero sem patriarcado é aquela coisa insossa, neutra, caretíssima. Gênero ficou um negócio descritivo, faltava politização. O patriarcado tal qual ele foi constituído pode não existir, mas a ideologia [patriarcal] perpassa por todas as instituições e relações sociais. O paradigma do masculino, do poder masculino, não dá para abrir mão. Porque senão você não explica como as mulheres hoje ainda são oprimidas do jeito que são. Isso não tem explicação sem considerar o patriarcado. Ela [a opressão] tem que ter uma explicação teórica. Eu não sou teórica, mas busco conhecer a teoria para ter explicação de como nós estamos hoje.

Eu acho ótimo gênero, não porque eu achei sempre, eu aprendi a gostar. No começo, quando a gente começou a estudar gênero, o pessoal comparava com os óculos. Gênero é esse tipo de óculos que nos ajuda a enxergar a realidade. E a gente precisa enxergar melhor a realidade para poder entendê-la.

Daniele Cordeiro Motta: O debate contemporâneo do feminismo tem dedicado importante atenção para as teorias imbricacionistas, tanto para pensar as análises acadêmicas quanto para pensar os processos de emancipação. Você é uma das que reivindica a teoria do Nó, elaborada por Saffioti. Você considera que o Nó é uma contribuição para esse paradigma interseccional?

Amelinha Teles: Eu acho que o feminismo interseccional que virou moda no feminismo dos Estados Unidos e no Brasil é muito bom. Eu gosto muito do feminismo interseccional ou das interseccionalidades porque é muito didático. Eu gosto daqueles exemplos da fábrica ${ }^{10}$. Eu acho legal, porque as pessoas entendem. A Heleieth Saffioti, a teoria do Nó, é o feminismo interseccional.

Imbricado quer dizer que, se você mexer em um, você mexe nos outros, ou pelo menos cutuca. E o interseccional também, de certa forma. E, didaticamente, talvez, seja mais fácil entender interseccionalidade do que o Nó. O Nó é tão apertado que as pessoas não enxergam, talvez com a interseccionalidade seja mais visível. Mas a vida é mais um nó do que intersecção. Porém, para mim, não há divergências entre um e o outro. Eu acho, para nós aqui, a Heleieth foi precursora dessa teoria. Chegou a do Nó primeiro, depois a interseccionalidade.

Raquel Oliveira Lindôso: E quando a ideia do Nó chega para você?

Amelinha Teles: Acho que chega na Constituição, que é 1986-87-88. E eu gosto dessa ideia do Nó [porque] nesse tempo, na Constituinte, nós militantes, porque militante tem necessidade primeiro, comparada com academia, temos que responder às coisas ali na lata.

E começou com as mulheres negras querendo se organizar, e as brancas liberais - porque tem umas brancas nojentas - começaram a criticar as mulheres negras. E eu confrontei de frente essas mulheres brancas. Esse racismo disfarçado me enche o saco, aí confrontei, chamei de sinhazinha e terminamos no maior bateboca, por causa das negras, e foi por ali que fui catar a Teoria do Nó. Aí ela [Saffioti] falava "mas o Brasil 
é racista mesmo". E eu questionava "até as feministas, Heleieth?". "Sim, as feministas! Amelinha, pensa dialeticamente, minha filha!".

É claro que vão lembrar mais da Lélia Gonzalez ${ }^{11}$ e Thereza Santos ${ }^{12}$, e isso é muito legítimo. Mas Heleieth me ensinou que branco e pobre é bem diferente de branco e rico. Acham que é uma coisa só, mas não é não. E a Heleieth mostrou pra gente que não dá para falar que aqui você é negra, aqui você é branca, aqui você é pobre. Não, tudo está ligado.

Daniele Cordeiro Motta: Tanto o patriarcado e quanto o Nó caíram no esquecimento. De que maneira você avalia esse apagamento?

Amelinha Teles: Na sociedade existe o patriarcado e capitalismo, ele foi diluído e responsabilizou mais individualmente as mulheres pela sua opressão. Quer dizer, o discurso da meritocracia é muito presente. "Eu aconteço, depende de mim". Esse discurso distorce a realidade e acaba influenciado a universidade, porque a universidade quer produzir trabalhos bonitos. Ficar falando de patriarcado, de opressão, é muito chato.

Vejo o debate sobre Hillary Clinton ${ }^{13}$ ser ou não feminista. O que é isso, gente?! Chamar aquela mulher de feminista! Nós construímos o feminismo a duras penas, agora as atrizes falam de feminismo. Isso aí é moda, já visto que o feminismo foi transformado em coisa chique. Hillary Clinton defendeu a guerra e uma mulher que defende guerra não pode ser considerada feminista. Nós somos contra guerra, somos radicalmente contra guerra. Ou, então, não entenderam nada de feminismo. Uma coisa é usarem os nomes, se apropriarem, manipularem, cooptarem e tal. Eu estou falando de feminismo como movimento de esquerda comprometido com determinados pontos muito definidos, entre esses a defesa da vida.

Raquel Oliveira Lindôso: O contexto atual é de imenso retrocesso no campo dos direitos das mulheres e das minorias, como você pensa os rumos possíveis para a luta anticapitalista, antipatriarcal e antirracista?

Amelinha Teles: Nós, as mulheres, nunca tivemos tanta igualdade política e jurídica como agora, e gostando ou não dos governos da Dilma e Lula ${ }^{14}$, é fato que houve uma política social voltada para as mulheres. Dilma, acho que não tem consciência disso, mas ela chegou na presidência graças ao movimento feminista. E a extrema direita, que é misógina, racista e lgbtranfósbica; não aceita que esses grupos sociais demandem e acessem direitos sociais e cidadania.

Eu vejo, portanto, que o cenário atual é uma reação a um certo avanço da sociedade brasileira em termos de direitos sociais. Eu nunca vi a sociedade brasileira reconhecer e conviver com tantas identidades democraticamente como agora. Eu tenho setenta e quatro anos e nunca vi. Sou uma pessoa sempre atenta à política nacional e estou sempre inserida, e afirmo que eu nunca vi um avanço tão importante. Ou seja, a direita não suportou os avanços democráticos e encontrou na figura de Bolsonaro a representação desse segmento social instalado na sociedade brasileira.

Eu me lembro que quem mais se preocupou com a democracia no Brasil foram às jovens feministas. Elas saíram com "Fora Cunha", em 2015. Na época eu participava da Comissão Nacional da Verdade (CNV) e estava com outros membros da CNV quando as jovens femininas passaram gritando e erguendo cartazes que diziam: "a buceta me pertence!". E eles disseram assim: "você acredita num movimento que põe isso aí em um cartaz? Eu falei: "Sim, esse eu acredito!". Foi o único movimento que gritou "Fora Cunha". E elas gritaram sozinhas.

Eu acho que, o nosso caminho, nós que vamos ter que fazer. Porque nós defendemos a vida e eles defendem a morte. Então, para mim é o seguinte: nós não podemos deixar que eles avancem mais. E depende de nós a nossa própria sobrevivência. Eles querem acabar com a humanidade, com o meio ambiente, educação e cultura. Eles querem que as pessoas não enxerguem.

E é a nossa vontade de defender a vida que vai determinar nosso caminho. Lembro do livro da Conceição Evaristo $^{15}$, "eles combinaram de nos matar e nós combinamos que não vamos morrer". E acho que nós combinamos que não vamos morrer, porque nós sempre defendemos a humanidade e as mulheres.

\section{Referências}

EVARISTO, C. Olhos D’água. Rio de Janeiro: Pallas; Fundação Biblioteca Nacional, 2016. 
FIRESTONE, S. The Dialectic of Sex: The Case for Feminist Revolution. New York: William Morrow and Company, 1970.

FRIEDAN, B. A Mística Feminina. Rio de Janeiro: Vozes, 1971.

GONZALEZ, L. O movimento negro na última década. In: GONZALEZ, L.; HASENBALG, C. Lugar de negro. Rio de Janeiro: Editora Marco Zero Ltda., 1982.

GONZALEZ, L. Racismo e sexismo na cultura brasileira. Revista Ciências Sociais Hoje, Anpocs, p. 223-244, 1984.

LARGUIA, I. Para uma Ciência da Libertação da Mulher. São Paulo: Global Editora, 1982.

MITCHELL, J. Psicanálise e feminismo: Freud, Reich, Laing e a mulher. Belo Horizonte, MG: Interlivros, 1979.

MITCHELL, J. Woman's estate. New York, NY: Random House, 1971.

SAFFIOTI, H. A mulher na sociedade de classes: mito e realidade. São Paulo: Expressão Popular, 2013 [1969].

SOUZA, P. Kimberle Crenshaw: A urgência da interseccionalidade. 2017. Ted Talks. (18m.53s). Disponível: https://www.youtube. com/watch?v=vQccQnBGxHU\&t=14s. Acesso em: 1 set. 2020.

\section{Notas}

1 A Comissão Nacional da Verdade (CNV) foi criada na gestão da presidenta Dilma Rousseff, e objetivou investigar as violações de direitos humanos cometidas pelo regime civil e militar, no período entre 18 de setembro de 1946 e 5 de outubro de 1988.

2 Betty Fridman (1971) publicou, em 1963, a obra The Feminine Mystique. Essa obra tornou-se um dos livros mais importante do século XX e referência para o período denominado como a segunda onda do feminismo.

3 O Pasquim foi um periódico semanal que surgiu no ano de 1969 com uma produção crítica à ditadura militar.

4 O jornal Brasil Mulher, criado em 1975, é pioneiro no campo da comunicação das mulheres e da luta feminista pela democracia.

5 Isabel Larguia (1982) é uma escritora cubana que em 1975 publicou a obra Hacia una ciencia de la liberación de la mujer.

6 Juliet Mitchell $(1971,1979)$ é uma psicanalista e feminista socialista britânica que escreveu os livros Woman's estate em 1971 e Psychoanalysis and feminism: Freud, Reich, Laing, and women em 1974.

7 Shulamith Firestone (1970) é uma escritora canadense que em 1970 escreveu o livro The Dialectic of Sex: The Case for Feminist Revolution.

8 Refere-se ao livro A Mulher na Sociedade de Classes: Mito e Realidade, publicado em 1969.

9 Refere-se à parte II A evolução da condição da mulher no Brasil.

10 Refere-se à elaboração da intelectual e ativista negra norte americana Kimberle Crenshaw (apud SOUZA, 2017) para cunhar o termo interseccionalidade. Para mais informações acessar o vídeo: https://www.youtube.com/watch?v=vQccQnBGxHU\&t=14s.

11 Lélia Gonzalez (1982) foi antropóloga, professora na Pontifícia Universidade Católica do Rio de Janeiro (PUC- RJ), militante do Movimento Negro Unificado (MNU); fundou o coletivo de mulheres Luisa Mahin no interior do MNU. Escreveu diversos textos, com destaque para "Racismo e Sexismo na cultura brasileira" de 1984 e "O movimento negro na última década" de 1982.

12 Thereza Santos foi teatróloga, atriz, professora, filósofa, carnavalesca e militante das temáticas raciais e de gênero. Thereza Santos é autora de diversos artigos sobre cultura e mulher negra, bem como sobre a diáspora dos povos africanos e negros e negras brasileiros.

13 Hillary Clinton concorreu, pelo partido democrata, ao cargo de presidenta dos Estados Unidos nas últimas. E perdeu para Donald Trump, do partido republicano.

14 O governo de Luiz Inácio Lula da Silva durou dois mandatos, entre 2003 e 2011. E os dois governos do presidente Lula foram marcados por diversas políticas sociais e inclusivas. O governo de Dilma Vana Rousseff, durou um mandato e meio, de 2011 a 2016. O segundo mandato da primeira mulher eleita no Brasil foi interrompido após um processo de impedimento (impeachment) marcado por irregularidades. Os governos de Lula e Dilma estão situados em um período histórico nomeado de "governos de esquerdas na América Latina". Esse período tem chamado atenção de pesquisadores e pesquisadoras de diversas áreas do saber dada a complexidade e ambivalência desses governos, como por exemplo a combinação entre políticas sociais e avanço do neoliberalismo.

15 Maria da Conceição Evaristo de Brito é uma escritora brasileira, nascida em Minas Gerais, que publicou vários romances, contos e poesias. O conto “A gente combinamos de não morrer” é parte do livro “Olhos D’Água”, publicado em 2014. 


\section{Raquel Oliveira Lindôso}

raquel.lindoso@yahoo.com.br

Mestra em Serviço Social pela Universidade Federal de Pernambuco (UFPE)

Doutoranda em Ciências Sociais pela Universidade Estadual de Campinas (UNICAMP)

\section{UNICAMP}

R. Cora Coralina, 100 - Cidade Universitária

Campinas - SP - Brasil

CEP: $13083-896$

\section{Daniele Cordeiro Motta}

daniele.motta@ifsp.edu.br

Doutora em Ciências Sociais pela Universidade Estadual Paulista (UNICAMP)

Professora Substituta de Sociologia do IFSP - Campus Capivari

\section{IFSP - Campus Capivari}

Avenida Doutor Ênio Pires de Camargo, 2971 - São João Batista

Capivari - SP - Brasil

CEP: $13360-000$

\section{Agradecimentos}

Gostaríamos de agradecer à Amelinha Teles pelo diálogo generoso e, especialmente, pela oportunidade de aprender com a luta feminista pela democracia, direitos sociais e cidadania. Agência financiadora

O presente trabalho foi realizado com apoio da Coordenação de Aperfeiçoamento de Pessoal de Nível Superior - Brasil (CAPES) - Código de Financiamento 001.

\section{Contribuições das autoras}

As autoras contribuíram igualmente para a elaboração do roteiro, execução e edição da entrevista.

Aprovação por Comitê de Ética e consentimento para participação

Não se aplica.

Consentimento para publicação

Consentimento das autoras.

Conflito de interesses

Não há conflito de interesses. 